\title{
建筑工程中高大模板支撑体系质量与安全的控制要点
}

张新力

广州市广州工程建设监理有限公司

DOI:10.32629/btr.v2i12.2711

[摘 要] 近年来,城市化发展速度明显加快,进一步促进了现代建筑行业的进步, 实现了建筑功能的多样性。且高层、超高层建筑与大跨度建筑 数量显著增加,直接提高了模板工程的建设要求, 特别是高大模板支撑体系的应用, 对于高层建筑和大跨度建筑结构的作用十分关键。但高大模 板支撑体系工艺复杂度较高, 要求施工作业人员能够灵活掌握, 采取必要的质量控制措施, 以确保施工现场的安全性。基于此, 文章将建筑工程高 大模板支撑体系作为主要研究内容, 重点阐述其质量与安全控制要点, 希望有所帮助。

[关键词] 建筑工程; 高大模板支撑体系; 质量控制; 安全控制; 要点

所谓高大模板支撑体系, 即建筑工程项目施工建设期间, 混凝土构件 施工模板支撑的高度超过 8 米, 且搭设的跨度不低于 18 米, 施工的总荷载量 每平方米不低于 $15 \mathrm{KN}$ 的模板支架工程项目。其中, 高大模板支撑体系常用 于建筑工程项目中, 但由于施工工艺复杂, 所以控制问题也备受关注。由此 可见, 深入研究并分析建筑工程高大模板支撑体系质量与安全的控制要点 十分有必要。

\section{1 工程项目概述}

广医五院直线加速器施工主要为直线加速器机房的结构及安装预留、 预埋的施工。本工程直线加速器机房结构设计通过墙和顶板钢筋混凝土的 厚度来防直线加速器的辐射, 墙厚分别为: $700 \mathrm{~mm}-1880 \mathrm{~mm}$, 基础底板面至直 线加速器顶板面的高度为 $5.7 \mathrm{~m} 、 6.9 \mathrm{~m}$; 直线加速器机房顶板厚度分别为: $1800 \mathrm{~mm} 、 3000 \mathrm{~mm}$ 属大体积混凝土施工。直线加速器机房混凝土强度等级: 本工程的混凝土结构的环境类别: 二 (a) 类、混凝土强度等级为 C 35 。本工 程高大模板工程均采用木模施工, 高大模板工程均采用扣件式钢管脚手架, 钢管型号为 $\phi 48.3 \times 3.6 \mathrm{~mm}$ 。本方案针对现场搭设高度 $8 \mathrm{~m}$ 及以上, 搭设跨度 $18 \mathrm{~m}$ 及以上, 施工总荷载 $15 \mathrm{kN} / \mathrm{m}^{2}$ 及以上, 集中线荷载 $20 \mathrm{kN} / \mathrm{m}$ 及以上的模板 支撑体系。

直线加速器机房模板工程概况:

\begin{tabular}{|c|c|c|c|c|}
\hline \multicolumn{5}{|c|}{ 直线加速器机房顶板 } \\
\hline $\begin{array}{c}\text { 梁截面尺寸 } \\
(\mathrm{mm})\end{array}$ & 板厚 $(\mathrm{mm})$ & 墙截面尺寸 $(\mathrm{mm})$ & $\begin{array}{c}\text { 柱截面尺寸 } \\
(\mathrm{mm})\end{array}$ & 层高 $(\mathrm{m})$ \\
\hline$/$ & $1800 、 3000$ & $700 、 1300 、 1760 、 1880 、 5600$ & $/$ & $5.7 / 6.9$ \\
\hline
\end{tabular}

注: 本方案针对梁截面积 $\geqslant 0.8 \mathrm{~m}^{2}$ 、板厚 $\geqslant 600 \mathrm{~mm}$ 和层高 $\geqslant 8.0 \mathrm{~m}$ 高大模板工程专项方案。

\section{2 高大模板支撑体系质量与安全的控制要点}

\section{1质量控制方面}

直线加速器机房模板工程高大模板支撑选择使用的是扣件式钢管 架支撑, 且剪力撑为加强型, 于一层板面设置立杆。而在搭设架体之前, 要求施工作业人员于一层板面定位并放样屋面梁板, 使支撑架体立杆排 设更准确。另外, 参考专项方案内容对屋面超重超跨梁立杆的纵距与横 距进行相应计算, 同时还包括屋面超高板的立杆纵距与横距。在立杆的 底部, 选择的是 12 \#的槽钢, 将其当成底座垫块, 要求立杆搭设接长不搭 接, 借助对接扣件的连接方式, 且临近两个立柱对接接头不允许在同步 之内, 要求对接接头沿着坚向错开距离超过 500 毫米, 同时不同接头的中 心与主节点的距离不应超过步距三分之一。针对屋面梁架体的外侧, 应 从底部到顶部科学设置连续的坚向剪力撑, 并于架体跨中另外设置钢管
格构柱, 使得架体稳定程度不断提高。于屋面板架体的外侧周边与内部 的底部到顶部也应当设置连续的坚向剪力撑, 将水平剪力撑设置在坚向 剪力撑的顶部交点部位。要求立杆底部与地面的距离为 200 毫米, 并沿着 纵横方向根据具体程序要求对扫地杆进行设计, 尽量保证扫地杆设置层 具被水平剪刀撑, 并且撑到架底。除此之外, 梁板架体水平支撑要经由水 平拉杆连接并组成一个整体, 确保架体和框架柱之间连接的可靠性, 拉 结预埋钢管连墙件, 有效规避架体搭设高度影响实际稳定性的程度。在 此基础上, 应安排专业工作人员, 对扭力扳手使用实施检查工作, 且拧紧 扭力矩需在 45-60N范围内。科学合理地将高大模板支撑体系的监测点设 置在架体临边的位置, 由专业工作人员在浇筑混凝土期间与养护期间系 统监测支撑体系。对于钢筋班组与木工班组, 开展支撑架体操作的过程 中, 坚决不允许集中堆放材料, 且材料上料一定要堆置均匀与平稳, 避免 集中力偏大而出现架体倜塌的情况。

\section{2安全控制方面}

(1) 原送硅安全措施。浇筑梁板时, 硂的堆积厚度不得超过模板设计 时的计算厚度。浇筑硂时, 必须安排专人对模板及其支架进行观察和维 护, 发现异常情况, 立即停止浇筑砤, 并卸载纠正变形模板后, 才能继续 浇筑硂。浇筑时硂输送管不得直接支承在钢筋、模板支架上, 原管下设 置废旧轮胎起缓冲作用, 水平管每隔 2 米用支架固定, 垂直或斜管用独立 钢管架固定。

(2) 施工安全技术措施。模板支撑系统施工前, 应按施工规范、施工方 案和施工组织设计的要求向搭设和使用人员做好安全、技术交底。对钢管 架、配件、加固件应进行检查验收, 严禁使用不合格的钢管架、配件。模 板支撑和脚手架搭设完毕后应进行检查验收, 合格后方准使用。泵送混凝 土时, 应随浇、随捣、随平整, 混凝土不得堆积在泵送管路出口处。拆除模 板脚手架时应采用可靠安全措施, 严禁高空抛掷。混凝土浇筑时, 安全员专 职负责监测模板及支撑系统的稳定性, 发现异常应立即暂停施工, 迅速疏 散人员, 及时采取处理措施, 待排除险情并经现场安全责任人检查同意后 方可复工。为规避混凝土浇筑冲击荷载偏大的影响, 可针对屋面混凝土浇 筑选择分层浇捣的方式, 要求每次的浇筑高度低于500毫米, 且保证梁中间 向两侧对称操作, 两层混凝土浇筑的时间差距不应超过 $2 \mathrm{~h}$, 只有这样, 才能 够确保混凝土粘结的质量达标。浇筑期间, 应选择汽车泵送混凝土, 且要求 材料随访随平, 坚决不允许堆积过长的时间。需要注意的是, 浇筑环节的施 工作业人员与操作作业人员数量不能过多, 主要与浇筑进度吻合即可, 以 降低施工的荷载。

(3) 安全检查。每天值班工长及安全员必须巡视工地, 对存在的安全隐 患及潜在的安全因素及时提出, 及时整改。发现违章行为, 及时纠正。 


\title{
绿色建筑工程的造价预算及其成本控制分析
}

\author{
关振宇 \\ 新疆生产建设兵团建设工程集团第一建筑安装工程有限责任公司 \\ DOI:10.32629/btr.v2i12.2733
}

[摘 要] 绿色建筑是指在建筑全寿命周期中充分实现环保、节能的建筑。绿色建筑工程合理的造价预算及其成本控制有利于降低工程开销, 提高建筑质量, 实现人与自然的和谐共处。随着经社会济的进步发展以及市场经济的日趋完善,人们越来越关注建筑工程成本控制和造价预算, 绿色建筑工程合理的造价预算及成本控制可以有效提高社会效益与经济效益,对节能环保有一定的推动作用。基于此,本文概述了绿色建筑,阐 述了绿色建筑工程造价预算与成本控制的特点,对绿色建筑工程造价的预算要点及其成本控制措施进行了探讨分析。

[关键词] 绿色建筑; 工程造价预算; 成本控制; 特点; 要点; 措施

绿色建筑工程与传统建筑工程有着明显的差异, 其具有保温隔热、节 能节水等功能, 并且可以有效处理排污、排水等问题, 满足生态环境建设要 求, 实现自然与人和谐发展的建筑。因此为了提高绿色建筑工程的经济效 益, 以下就绿色建筑工程造价预算及成本控制进行了探讨分析。

\section{1 绿色建筑的概述}

绿色建筑的 “绿色” 并不是指一般意义的立体绿化、屋顶花园, 而是 代表一种概念或象征, 指建筑对环境无害, 能充分利用环境自然资源, 并且 在不破坏环境基本生态平衡条件下建造的一种建筑, 又可称为可持续发展 建筑、生态建筑、回归大自然建筑、节能环保建筑等。绿色建筑的特征主 要体现在：

(1) 自然和谐。自然和谐就是人们在建造、使用建筑的过程里, 爱护、 亲近所处的自然环境, 使人、自然、建筑三者和谐共存。只有如此才可以 兼顾协调环境效益、经济效益和社会效益; 才可以实现人类社会、生态环 境的可持续发展。

（2）节约环保。节约环保指的是人们在建造、使用建筑的时候, 尽可能 地节省资源利用, 保护周围环境, 呵护生态, 减少对环境的污染, 把由于人 类对建筑建造与使用活动造成的对环境和资源的负荷与影响减到最小程 度和生态再创造能力的范围内。

（3）健康舒适。建立一个健康舒适的生活工作环境, 是人们建造、使用 建筑的基本要求。要给人们提供健康、舒适和高效的空间。

\section{2 绿色建筑工程造价预算与成本控制特点的分析}

绿色建筑工程造价预算与成本控制特点主要体现在:

(1) 绿色建筑工程造价预算特点的分析。因绿色建筑工程难度增加, 相对应的造价因素也会随之增多。在此工程项目中, 工程造价主要包含工

（4）环境保护措施。加强对现场施工人员的环保意识教育, 在硅震捣过 程中要尽量避免震动钢筋及模板, 尽可能避免发出不必要的施工噪音, 最 大限度地减少施工噪音对环境的污染。废弃的模板及方木应及时收集清理, 要做到工完场清。楼层模板拆除完后, 楼层内的废料垃圾均应清理出楼层, 运至堆放场。现场木作余料要尽量利用, 不能再利用的要及时送到回收站。

\section{3 结束语}

综上所述, 高大模板支撑体系的质量和安全控制工作涵括多个环节, 且具有系统性特征, 不管是哪一环节发生问题, 均会对项目整体效果产生 不利的影响。在这种情况下, 必须积极贯彻并落实相关工作, 只有这样, 才 能够确保建筑工程高大模板支撑体系施工建设的安全性, 进一步优化项目 的施工效果。

[参考文献]
程材料选配方面的造价和工程施工方面的造价。此工程项目需要考虑周边 的绿化、交通情况以及选址方案, 所以在造价方面应做更具体的预算。

(2) 绿色建筑工程成本控制特点的分析。成本控制的主要特点为随着 施工过程中出现的问题逐渐增多, 对其管理也会逐渐增加难度, 与其相对 应的管理因素也会变得多样、复杂起来, 这对工程建设非常不利。造成这 一现象的原因是绿色建筑工程项目比传统建筑工程项目要求较高, 由于需 要保证此工程达到节能环保的效果, 所以在此工程项目中需要思考的因素 随之增多, 所涉及的内容增多, 造成此新型工程项目比传统工程项目难度 更高, 形成更复杂的局面。比如在施工过程中, 面临占地面积较大的问题, 需要开拓更多的土地资源, 使得增加了成本。在此工程中, 需要考虑采光、 环保材料、植物、地形等因素, 必须增加工程项目的资金, 才能够顺利的完 成绿色建筑工程项目。

\section{3 绿色建筑工程造价的预算要点及其成本控制措施分析}

3. 1 绿色建筑工程造价预算要点分析。为了保障绿色建筑工程造价预 算的有效性, 笔者认为需要做好以下几点工作:

(1) 加强预算动态管理。建筑单位要多角度地、全方位地分析处理 工程预算工作中 “量” 与 “价” 的变动, 要对建筑工程的周期变化情况 做到心中有数, 并且要对市场的客观情况进行认真的分析, 其后再在此 基础上提出有针对性的解决对策, 尽可能地发挥出工程造价预算的实际 功能。

（2）做好图纸预算编制工作。编制人员要实地勘察建筑项目的现场情 况, 对工程的现场情况进行综合预算编制。

(3) 提升从业人员的专业能力。因为绿色建筑工程的造价预算工作具 有复杂性、技术性以及系统性等特征, 所以相关工作人员要具备较高的业

[1]张蓄.浅谈建筑工程高大模板支撑系统施工安全管理[J].装饰装修 天地,2019,(20):73.

[2]朱应君.高大模板支撑体系施工安全质量与控制分析[J].建筑工程 技术与设计,2019,(18):2342.

[3]周中建.高大模板支撑体系施工安全质量及其控制 [J].低碳世 界,2019,9(4):124-125.

[4]曾涛.建筑工程高大模板支撑体系施工安全质量与控制研究[J].建 筑工程技术与设计,2019,(23):2409.

[5]邹俊星.建筑工程高大模板支撑体系安全施工工艺 及控制措施探 讨 [J].建材与装饰,2019,(16):222-223.

[6]刘国辉,路龙伟.扣件式钢管高大模板支撑体系的施工技术及其管 理分析[J].建材与装饰,2019,(16):48-49. 